\title{
Possible impacts of spring sea surface temperature anomalies over South Indian Ocean on summer rainfall in Guangdong- Guangxi region of China
}

\author{
Dachao Jin $^{1}\left(\mathbb{0} \cdot\right.$ Zhaoyong Guan $^{1} \cdot$ Liwei Huo $^{1} \cdot$ Xudong Wang $^{1}$
}

Received: 23 April 2016 / Accepted: 5 December 2016 / Published online: 3 January 2017

(c) The Author(s) 2017. This article is published with open access at Springerlink.com

\begin{abstract}
Based on observational and reanalysis data for 1979-2015, the possible impacts of spring sea surface temperature anomalies (SSTA) over the South Indian Ocean on the inter-annual variations of summer rainfall in Guangdong and Guangxi Provinces (i.e., the GuangdongGuangxi area, GG) were analysed in this study. The physical mechanism behind these impacts was explored. Two geographic regions over $\left[65^{\circ} \mathrm{E}-95^{\circ} \mathrm{E}, 35^{\circ} \mathrm{S}-25^{\circ} \mathrm{S}\right]$ and $\left[90^{\circ} \mathrm{E}-110^{\circ} \mathrm{E}, 20^{\circ} \mathrm{S}-5^{\circ} \mathrm{S}\right]$ were defined as the western pole region and the eastern pole region, respectively, for the GG summer precipitation $\left(\mathrm{P}_{\mathrm{GG}}\right)$-related South Indian Ocean dipole SSTA pattern (R-SIODP). The difference between springtime SST anomalies averaged over the western pole region and that averaged over the eastern pole region was defined as the R-SIODP index. The correlation between the spring R-SIODP index and GG summer precipitation can reach up to 0.52 . In the spring of positive R-SIODP anomaly, southerly winds over the western pole of the R-SIODP weaken, whereas the southeast trade winds over the eastern pole strengthen. By means of the wind-evaporation-SST feedback mechanism, the enhanced southeast trade winds can weaken the evaporation over the western pole of the R-SIODP and enhance the evaporation over the
\end{abstract}

Zhaoyong Guan

guanzy@nuist.edu.cn

Dachao Jin

jindc@nuist.edu.cn

1 Key Laboratory of Meteorological Disaster, Ministry of Education (KLME)/Joint International Research Laboratory of Climate and Environment Change (ILCEC)/ Collaborative Innovation Center on Forecast and Evaluation of Meteorological Disasters (CIC-FEMD), Nanjing University of Information Science and Technology, Nanjing 210044, China eastern pole. This results in a sustained positive SSTA in the western pole of the R-SIODP and a sustained negative SSTA in the eastern pole, whereby the distribution of the SSTAs maintains until summer. The SST dipole abnormally enhances the cross-equatorial airflow near $105^{\circ} \mathrm{E}$, which intensifies the anomalous anti-cyclonic circulation over South China Sea at $850 \mathrm{hPa}$ and simultaneously results in abnormal enhancement of water vapour transport to GG. Additionally, the SST dipole promotes abnormal divergence in the lower troposphere and abnormal convergence in the upper troposphere over the maritime continent (MC) region. Moreover, the low-level convergence in GG is enhanced, which results in abnormal enhancement of ascending motion in the GG that is conducive to positive summer rainfall anomaly in this region. In this study, the spring R-SIODP index, the SST to the east of Australia and to the east of southern Africa, and the North Atlantic oscillation (NAO) index were used to construct a statistical prediction model for the inter-annual variability of the GG summer rainfall anomaly. This model can well predict the accuracy of the inter-annual variation of GG summer rainfall.

Keywords Spring dipole SSTA pattern · South Indian Ocean $\cdot$ Summer rainfall in Southern China $\cdot$ Inter-annual variation

\section{Introduction}

China is a vast country where climate and inter-annual climate variability differ significantly from area to area (Zou et al. 2005; Zhai et al. 2010; Jin et al. 2015). Guangxi Autonomous Region and Guangdong Province (GG, hereafter) is the region where most rainfall occurs in the 
summer, and the inter-annual variability of summer rainfall in this region is the largest in China (Jin et al. 2015; Huo and Jin 2016). It is estimated that the average percentage of summer rainfall over the entire year in this area is relatively high (up to $47 \%$ ) and the inter-annual variability is also high (the mean square root is $176.93 \mathrm{~mm}$ ) (Fig. 1a). GG has a highly developed economy and a large population, thereby and the amount of summer rainfall has an important impact on local residential life as well as societal and economic development. A better understanding and accurate prediction of GG summer rainfall is of significant importance.

Significantly locally rainfall has been found in GG (Zou et al. 2005; Zhai et al. 2010; Jin et al. 2015). Studies indicate a multi-scale temporal variation in precipitation in the area $\left(\mathrm{P}_{\mathrm{GG}}\right)$ during the summer (Fig. 1b, c) and that there is no significant correlation between $\mathrm{P}_{\mathrm{GG}}$ and summer rainfall in other regions (Jin et al. 2015). The GG rainfall anomaly is affected by many factors. For example, since the late 1970s, there has been a significant correlation between the GG summer rainfall anomaly and the Indian Ocean-Pacific Ocean sea surface temperature anomaly (SSTA). When positive SSTA occurs in the equatorial central Pacific and negative SSTA occurs in the maritime continent (MC), the Hadley circulation in East Asia weakens. That is, the abnormal subsidence in the MC region and the abnormal ascending motion in GG can facilitate the occurrence of positive summer rainfall anomalies (and vice versa) (Wu et al. 2012). Furthermore, the SST anomalies over the maritime continent can affect the rainfall anomaly over GG region via modifying the cross-equatorial flows (Chen et al. 2014a, b; He and Wu 2014).

It was reported that the co-occurrence of El Niño event and the positive phase of the Pacific decadal oscillation (PDO) (Mantua et al. 1997) could lead to the intensification and westward shift of the Western Pacific subtropical high, which subsequently induces lower than normal summer rainfall in GG region. On the contrary, when La Niña event co-occur with the negative phase of the PDO, rainfall will be higher than normal in GG (Chan and Zhou 2005). It is interesting that the anomalous summer rainfall in GG region varies in-phase (out-of-phase) with the precursory winter rainfall anomaly during the El Nino/La Nina decaying (developing) years (Wu et al. 2014).

Previous studies primarily focused on the impact of the SSTA in tropical areas and the effect of the atmospheric circulation anomaly in the northern hemisphere on the rainfall anomaly in southern China (e.g., Guan et al. 2011; Guan and Jin 2013; Jin et al. 2013; Wang et al. 2016, 2017). However, in recent years, impacts of SSTA and the atmospheric circulation anomaly in the southern hemisphere have received increasing attention (e.g., Nan and Li 2003; Yang and Ding 2007; Zheng and Li 2012; Xu et al. 2013; Cao

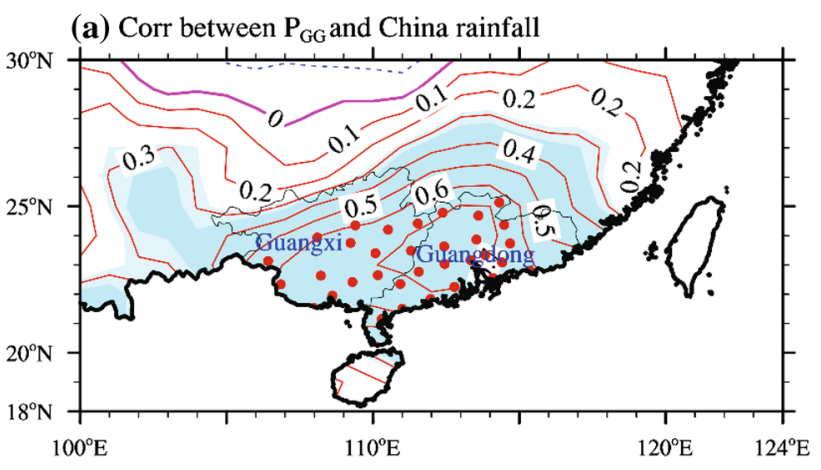

(b) Time series of $\mathrm{P}_{\mathrm{GG}}$ (Unfiltered)
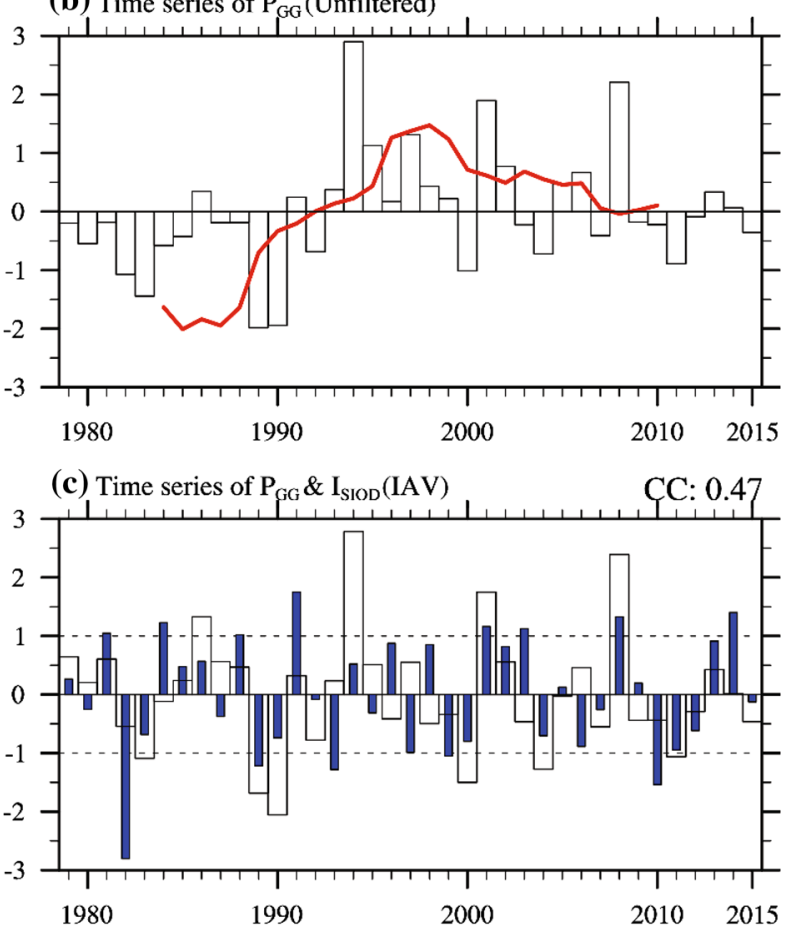

Fig. 1 Simultaneous correlations of the regional mean rainfall over Guangdong-Guangxi with the southern China rainfall during boreal summer (JJA) (a). Lighter (darker) shades indicate areas where correlation coefficients are statistically significant at/above the $95 \%$ (99\%) confidence level. Red dots show the locations of 36 meteorological stations in Guangdong-Guangxi region. Blue, magenta and red lines are for negative, zero and positive contour values, respectively. The contour interval is 0.1. Shown in (b) are the standardized time series (bars) of summer rainfall anomaly in GuangdongGuangxi region and its 11-year running mean (red line). In (c) shown are the standardized time-series of inter-annual variations of summer rainfall in Guangdong-Guangxi region (broader bars) and MAM SIOD indices derived from HadiSST data (narrower blue bars). The rainfall anomalies in (a) and (b) are unfiltered. Components of longterm trends and periods longer than 9 years in rainfall anomalies and in SIOD signals are all removed in (c)

et al. 2014; Chen et al. 2014a, b; Feng et al. 2014; He and Wu 2014; Wu et al. 2015). In the Indian Ocean, two dominant signals in the southern hemisphere, i.e. the Antarctic oscillation (Gong and Wang 1999) and the South Indian 
Ocean dipole (SIOD) (Behera and Yamagata 2001), have been found.

The Antarctic oscillation is a primary mode of atmospheric circulation in the southern hemisphere. A positive Antarctic oscillation anomaly during the preceding winter can result in positive SSTA in the middle latitudes of the southern hemisphere through the wind-evaporation-SST feedback mechanism (WES) (Xie and Philander 1994). This causes the positive SST anomalies to be sustained until the subsequent spring, which results in abnormal subsidence and less than normal rainfall in southern China. On the contrary, the rainfall is above normal during the period of negative Antarctic oscillation (Zheng and Li 2012). The Antarctic oscillation anomaly also could lead to anomalous winter rainfall in southern China (Wu et al. 2015).

The SIOD is an important air-sea coupling phenomenon (Behera and Yamagata 2001). The primary manifestation of the SIOD is the oscillation of the SSTA in the Indian Ocean (Southern Hemisphere) in an east-west direction. This dipole-type oscillation in an east-west direction of the SSTA in the subtropical South Indian Ocean can affect winter rainfall anomaly in southern China during the same period (Chen et al. 2014a, b). The spring SIOD can be used as an impact factor to predict the summer rainfall anomaly in eastern China (Yang and Ding 2007). In the summer, by modulating the anomalous circulations over the Arabian Sea and the Bay of Bengal, the SIOD can affect the water vapour transport and vertical motion anomalies over the Indochina Peninsula and henceforth affect summer rainfall in southwestern China (Cao et al. 2014). By modulating the Mascarene high (Feng et al. 2014), the SIOD is also found to affect the Indian Ocean dipole (IOD) (Saji et al. 1999) that has a close relationship with summer climate anomalies in East China (Guan and Yamagata 2003).

Possible connections could be found between variations of summer rainfall in southern China and the SIOD. By far, limited efforts have been made to investigate the relationship between the SIOD and the variation of summer rainfall in China after the long-term trend is removed (e.g., Yang and Ding 2007). Note that in the study of Yang and Ding (2007), the decadal signal was not filtered out when the relationship between the SIOD and inter-annual variability of rainfall in China was examined. However, due to both the significant decadal and inter-annual variations of rainfall in South China (e.g., Wu et al. 2010, 2012; Duan et al. 2013), it is not reasonable to keep both the linear trend and the decadal variation in time-series of physical variables such as the SIOD index in the attempt to analyse the relationship between the SIOD and the variation of summer rainfall in China and the mechanisms behind on the inter-annual timescale. Wu et al. (2012) analysed the relationship between the rainfall in southern China and the equatorial Indian OceanPacific Ocean inter-annual variability but did not discuss in detail the physical mechanism for the SIOD impacts on the rainfall in southern China. Cao et al. (2014) examined how the summer SIOD influences rainfall variations in southwestern China during the same period but paid no attention to rainfall anomalies in other areas. The aforementioned studies indicated that there is indeed a significant connection between the SIOD and the rainfall anomaly in China. Figure 1c shows interannual variations of the summer SIOD index and $\mathrm{P}_{\mathrm{GG}}$ during1979-2015. The correlation coefficient between SIOD index and $\mathrm{P}_{\mathrm{GG}}$ is 0.47 .

The relationship between GG summer rainfall and the SIOD index has been explored as mentioned above. However, is it possible to find the relationship of the GG summer rainfall anomalies and the precursor SST signal in the South Indian Ocean as the predictive factor? What are the possible mechanisms behind this relationship? In the present paper, we investigate these possibilities by looking at the spring SSTA change in the South Indian Ocean and its association with the summer rainfall anomaly over GG on the inter-annual timescale.

This paper is organized as follows. Sect. 1 describes the motivation of this study. Sect. 2 introduces the data and method that were used. In Sect. 3, the relationship between GG summer rainfall and SSTA in the South Indian Ocean (SIOSSTA) is examined. In Sect. 4, the mechanism behind the GG rainfall-SIOSSTA relation is discussed. In Sect. 5, a statistical model is constructed and the seasonal prediction of GG summer rainfall is presented. Finally, discussion and conclusions are provided in Sect. 6.

\section{Data and methodology}

The data used in the present study include rainfall, SST, and some other circulation data. The daily precipitation data collected at 36 stations in the GG area were extracted from the dataset of 753 stations in China for 1979-2009 (Fig. 1a) released by the China Meteorological Administration and from the meteorological information comprehensive analysis and process system (MICAPS) 3.0 for 2010-2015. The monthly rainfall data (horizontal resolution: $2.5^{\circ} \times 2.5^{\circ}$ ) of the Climate Prediction Center Merged Analysis of Precipitation (CMAP) (Xie and Arkin 1997), the Global Precipitation Climatology Project (GPCP) (Adler et al. 2003) for 1979-2015, and the ERA-Interim reanalysis data (horizontal resolution: $1.5^{\circ} \times 1.5^{\circ}$ ) (Dee et al. 2011) for the same period were also used in this study.

The monthly SST data for 1979-2015 from the Met Office Hadley Center (Rayner et al. 2003) (horizontal resolution: $1^{\circ} \times 1^{\circ}$ ), the Extended Reconstructed Sea Surface Temperature V3b data from the National Oceanic and Atmospheric Administration (NOAA) (Smith et al. 2008) (horizontal resolution: $2^{\circ} \times 2^{\circ}$ ), the Cosmic Background 
Explorer's (COBE) SST data (Ishii et al. 2005) (horizontal resolution: $1^{\circ} \times 1^{\circ}$ ), and the monthly Optimum Interpolation Sea Surface Temperature V2 (OISST) data for 1982-2015 (Reynolds et al. 2002) (horizontal resolution: $1^{\circ} \times 1^{\circ}$ ) were also utilized in this study. The GODAS data from the National Centers for Environmental Prediction (NCEP) Global Ocean Data Assimilation System (Saha et al. 2006) along with the downward and upward shortwave radiation, and the surface latent heat flux from NCEP/ NCAR I (Kalnay et al. 1996) were analyzed to diagnose the oceanic mixed layer heat budget. and the summer season means June-August (June-JulyAugust; JJA).

In the present paper, the temperature tendency of the ocean mixed layeaddition to their long-term trendsr was diagnosed. The equation of ocean mixed layer heat budget can be written as follows:

$\frac{\partial T^{\prime}{ }_{0}}{\partial t}=-T^{\prime}{ }_{a d v}-T^{\prime}{ }_{u p w}+\frac{S W R^{\prime}}{\rho C_{p} H_{m}}+\frac{L H^{\prime}}{\rho C_{p} H_{m}}+R^{\prime}$,

$T_{a d v}^{\prime}=\left(u_{0}^{\prime} \frac{\partial \bar{T}_{0}}{\partial x}+\bar{u}_{0} \frac{\partial T_{0}^{\prime}}{\partial x}+u_{0}^{\prime} \frac{\partial T_{0}^{\prime}}{\partial x}\right)+\left(v^{\prime}{ }_{0} \frac{\partial \bar{T}_{0}}{\partial y}+\bar{v}_{0} \frac{\partial T_{0}^{\prime}}{\partial y}+v_{0}^{\prime} \frac{\partial T_{0}^{\prime}}{\partial y}\right)$,

The North Atlantic Oscillation (NAO) index data (Hurrell 1995) were collected from PSD (http://www.esrl.noaa. gov/psd/data/correlation/nao.data). The Nino3.4 index used in this paper is the regional average SSTA in the geographic region $\left[170^{\circ} \mathrm{W}-120^{\circ} \mathrm{W}, 5^{\circ} \mathrm{S}-5^{\circ} \mathrm{N}\right]$. Since the precursor El Niño-Southern Oscillation (ENSO) signal can affect the Indian Ocean SSTA (e.g., Xie et al. 2009), the impact of the ENSO signal indicated by the Nino3.4 index in the preceding winter (from December of the preceding year to February of the current year) was excluded by using the linear regression method in our analysis. A variable $F$ is composed of the precursory ENSO signal related component and the residual, which can be expressed as:

$F=a I_{\text {Nino } 3.4}+F_{\text {noENSO }}$

In Eq. (1), $I_{\text {Nino3.4 }}$ stands for the normalized time series of the preceding winter ENSO index. $F_{\text {noENSO }}$ stands for the residual value of the variable $F$ after the preceding ENSO signal is removed. Coefficient $a$ is the covariance of $F$ and $I_{\text {Nino3.4. }}$.

In addition to their long-term trends (Yang and Ding 2007; Hsu and Lin 2007), there also exist significant decadal variations in GG summer rainfall and the SIOD index (Fig. 1b) (Wu et al. 2012; Duan et al. 2013). To investigate the interannual variation in GG summer rainfall and its relationship with the SSTA over the South Indian Ocean, time series were pre-processed by filtering out the decadal and long-term trends but in Fig. 1a, b. The decadal variation component was removed by using a 9-year running mean whereas the linear long-term trend was removed by performing the regressions. Unless otherwise specified, the summer rainfall, SST field, and circulation fields for GG used in the following discussion are all components of inter-annual variability. The spring season referred to in this paper means March-May (March-April-May; MAM), and

$T^{\prime}{ }_{u p w}=w_{0}^{\prime} \frac{\partial \bar{T}_{0}}{\partial z}+\bar{w}_{0} \frac{\partial T_{0}^{\prime}}{\partial z}+w_{0}^{\prime} \frac{\partial T_{0}^{\prime}}{\partial z}$

In the Eq. (2), the over-bar and prime denote the mean climatology and anomaly respectively. The zonal, meridonal, and vertical components of ocean current are respectively represented by $u_{0}, v_{0}$, and $w_{0}$ whereas $T_{0}$ is for the mixed layer temperature. The net shortwave radiation $(S W R)$ is defined as the difference between downward and upward shortwave radiation fluxes while $L H$ is the surface latent heat flux. $H_{m}$ is the ocean mixed layer depth whereas $R$ is the residual. The density of sea water $\rho_{0}$ is set to $10^{3} \mathrm{~kg} / \mathrm{m}^{3}$, and the specific heat of sea water $C_{p}$ is $4000 \mathrm{~J} / \mathrm{Kg} \mathrm{K}$. On the right hand side of Eq. (2), terms and $T^{\prime}{ }_{a d v}$ and $T^{\prime}{ }_{u p w}$ are anomalies related to the ocean advection and upwelling. All the terms in Eq. (2) are averaged values in the vertical dimension for the mixed layer. More details can be found in the literature such as in Chen et al. (2016) and Wu et al. (2006).

\section{Relationship between GG summer rainfall and the South Indian Ocean SSTA}

The GG summer rainfall is significantly and positively correlated with the spring South Indian Ocean SSTA in the middle latitudes, and negatively correlated with the tropical southeastern Indian Ocean SST. These significant correlations persist from spring to summer (Fig. 2). The spatial distribution of the correlation is similar to that of the SIOD (Behera and Yamagata 2001) except that the central locations of large values for the correlation coefficient differ from the SIOD defined by Behera and Yamagata (2001). In this paper, the high correlation areas $\left[65^{\circ} \mathrm{E}-95^{\circ} \mathrm{E}\right.$, $\left.35^{\circ} \mathrm{S}-25^{\circ} \mathrm{S}\right]$ and $\left[90^{\circ} \mathrm{E}-110^{\circ} \mathrm{E}, 20^{\circ} \mathrm{S}-5^{\circ} \mathrm{S}\right]$ in Fig. $2 \mathrm{a}$ were selected as the western and eastern pole regions of the SIOD-like pattern respectively. We refer this SIOD-like 

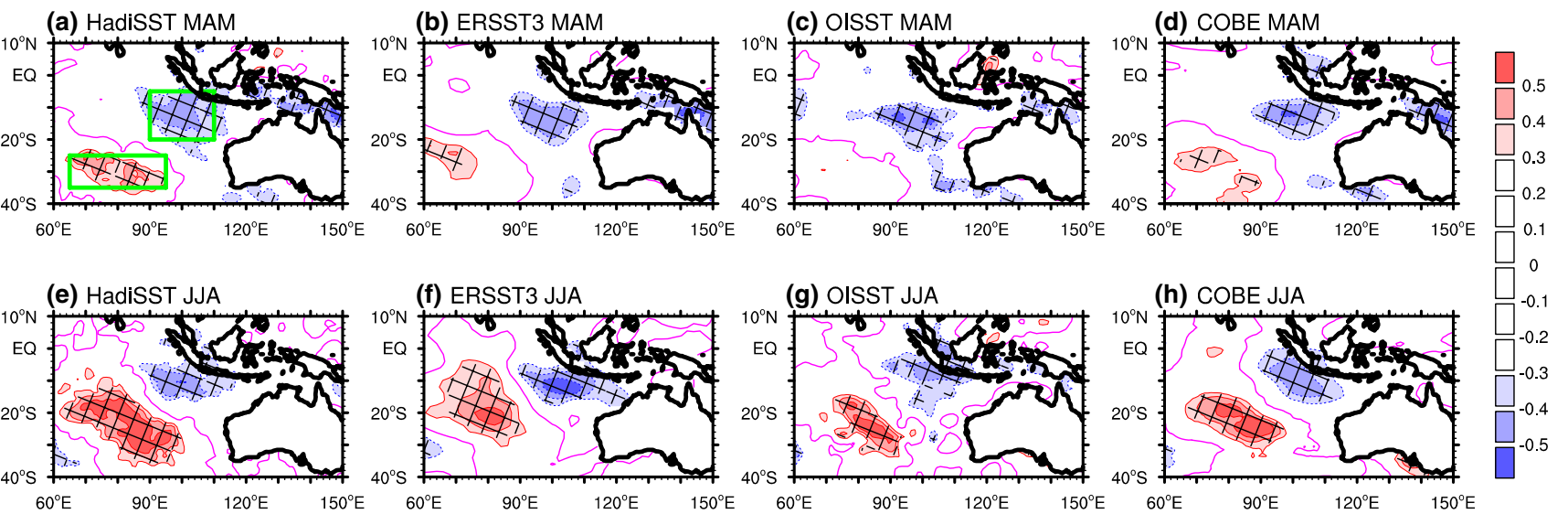

Fig. 2 Correlations of summer rainfall in Guangdong-Guangxi region with the southern Indian Ocean SSTA. In upper panels shown are for spring, which are derived from HadiSST (a), ERSST (b), OISST (c) and COBE (d) datasets, respectively. In lower panels are

same as in upper panels but for summer. Shaded areas with hatchedlines denote where the correlation coefficients exceed $95 \%$ confidence level using a $t$ test
Fig. 3 Normalized time series of regional mean summer rainfall (open bars) over GG region and that of spring $\mathrm{I}_{\mathrm{R}-\mathrm{SIODP}}$ (narrower red bars)

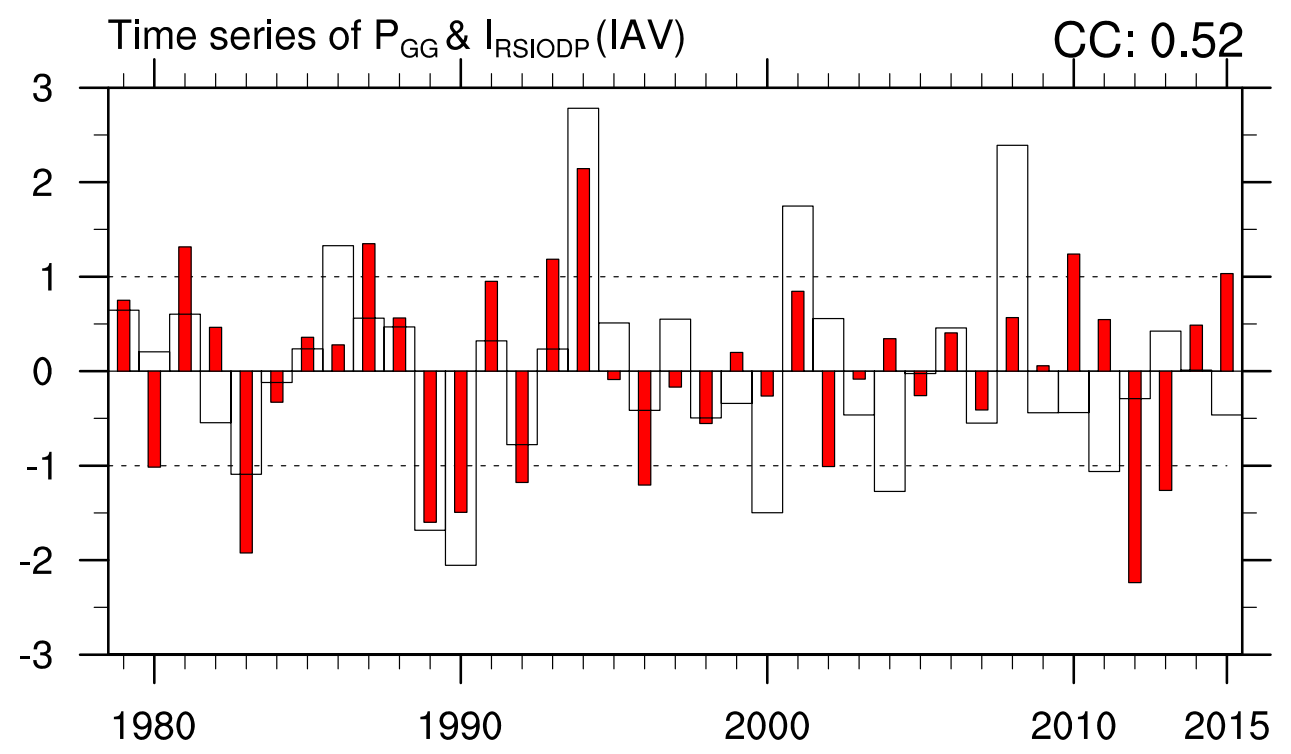

SSTA pattern as the summer $\mathrm{P}_{\mathrm{GG}}$-related SIOD SSTA pattern (R-SIODP for abbreviation). Thus, the R-SIODP index was defined as follows:

$I_{\mathrm{R}-\mathrm{SIODP}}=[S S T A]_{\mathrm{W}}-[S S T A]_{\mathrm{E}}$,

where $[S S T A]_{\mathrm{W}}$ and $[S S T A]_{\mathrm{E}}$ indicate the regional averages of springtime SSTA in the western and eastern pole areas, respectively. The standard deviations of $[S S T A]_{\mathrm{W}}$ and $[S S T A]_{\mathrm{E}}$ were found to be $0.27 \mathrm{~K}$ and $0.24 \mathrm{~K}$ respectively. Note that they are comparable in magnitude. A positive (negative) $\mathrm{I}_{\mathrm{R}-\mathrm{SIODP}}$ means the SST anomaly over the western (eastern) pole is greater than that over the eastern (western) pole SST. It was found that the $I_{\mathrm{R} \text {-SIODP }}$ and $\mathrm{P}_{\mathrm{GG}}$ time series (Fig. 3) vary in-phase; the correlation coefficient between spring $I_{\mathrm{R}-\mathrm{SIODP}}$ and summer $\mathrm{P}_{\mathrm{GG}}$ is 0.52 .
Table 1 Lagged and simultaneous correlations of the regional mean summer (JJA) rainfall over GG region with R-SIODP index

\begin{tabular}{|c|c|c|c|c|}
\hline \multirow[t]{2}{*}{ Correlations } & \multicolumn{3}{|c|}{ 1979-2015 } & \multirow{2}{*}{$\begin{array}{l}\text { 1982-2015 } \\
\text { OISST }\end{array}$} \\
\hline & HadiSST & ERSST & COBE & \\
\hline $\mathrm{P}_{\mathrm{GG}}$ with $I_{\mathrm{R}-\mathrm{SIODP}(\mathrm{MAM})}$ & 0.52 & 0.46 & 0.51 & 0.47 \\
\hline $\mathrm{P}_{\mathrm{GG}}$ with $I_{\mathrm{R}-\mathrm{SIODP}(\mathrm{JJA})}$ & 0.47 & 0.35 & 0.38 & 0.43 \\
\hline
\end{tabular}

The critical values at $99 \%, 95 \%$, and $90 \%$ confidence levels are found to be $0.42,0.33$, and 0.28 for $1979-2015$, and $0.44,0.34$, and 0.29 for 1982-2015, respectively

The correlation of the R-SIODP and the $\mathrm{P}_{\mathrm{GG}}$ persists from spring to summer. In fact, the correlation of $\mathrm{P}_{\mathrm{GG}}$ with the $\mathrm{I}_{\mathrm{R} \text {-SIODP }}$ is significant. Table 1 shows the correlation 
coefficients of summer $\mathrm{P}_{\mathrm{GG}}$ with both springtime and summertime R-SIODP indices. It is seen that the correlation coefficient between the spring SST index and summer $\mathrm{P}_{\mathrm{GG}}$ is 0.52 whereas it is 0.47 between the JJA SST index and $\mathrm{P}_{\mathrm{GG}}$ using HadiSST data. The spatial structures of the correlation coefficients between $\mathrm{P}_{\mathrm{GG}}$ and SST data derived from different data from different data agencies are relatively consistent (Fig. 2), which indicates that these results are reliable and independent of SST data sources.

The pattern persistence can further be examined by correlations between spring SSTA and summer SSTA (Fig. 4). It is seen that higher correlations are found in both the eastern and western poles of the R-SIODP, indicating a relatively stable persistence of SSTA in the South Indian Ocean (Fig. 4). The correlation coefficient between the spring and summer SSTs on most grid points of the western pole exceeds 0.40 (significant at/above the $95 \%$ confidence level). In the eastern pole, the correlation coefficient at most grids is higher than 0.60 and can even reach up to 0.80 . The above results indicate that the R-SIODP in the spring can continue in the summer.

In addition, compared to the other three SST datasets, the best correlation is found between $\mathrm{P}_{\mathrm{GG}}$ and the R-SIODP index calculated using HadiSST data (Fig. 3; Table 1). The correlation between the spring and summer R-SIODPs is also the best (Fig. 4). Therefore, the R-SIODP index discussed in the following analysis was calculated based on the HadiSST data.

The spring SSTA in the South Indian Ocean possible has impacts on $\mathrm{P}_{\mathrm{GG}}$. This can be displayed by the correlation distribution between the spring R-SIODP index and summer rainfall in southern China (Fig. 5). The correlation coefficient is positive and statistically significant with the maximum value exceeding 0.40 at the border of GG (Fig. 5a) when using the in situ station rainfall data. The correlations of the spring R-SIODP index with other rainfall anomalies from the CMAP and GPCP summer rainfall data exhibit similar spatial patterns (Fig. 5b, c).

\section{Mechanism for the impact of the spring R-SIODP on GG summer rainfall}

As mentioned above, significant positive correlations are found between the spring R-SIODP index and GG summer rainfall anomalies. To clarify how the spring R-SIODP affects the GG summer rainfall anomaly, composite and regression analyses were performed to explore the relations between SSTA and the circulation anomalies. It was found that the standard deviation of the spring R-SIODP index is

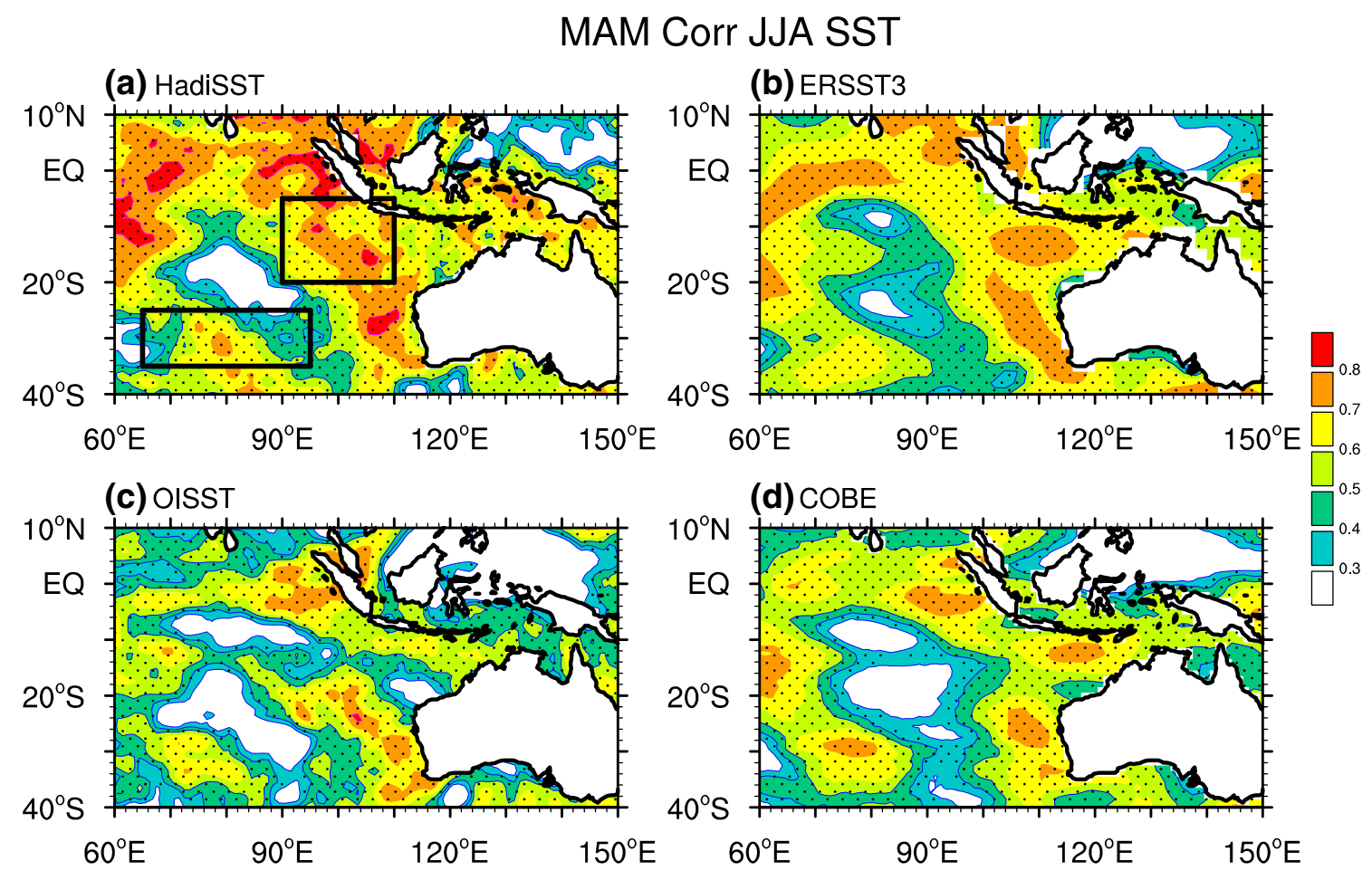

Fig. 4 Correlations of SSTA at a particular grid point during springtime with those in summertime at the same grid point. Stippled areas are for the correlations significant at/above $95 \%$ level of confidence using a $t$ test 
(a) Corr between $I_{S I O D}$ and in situ

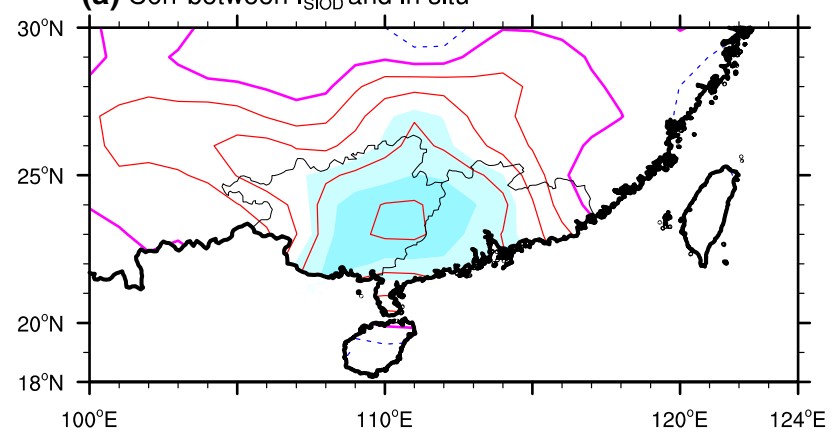

(b) Corr between $I_{\mathrm{SIOD}}$ and CMAP

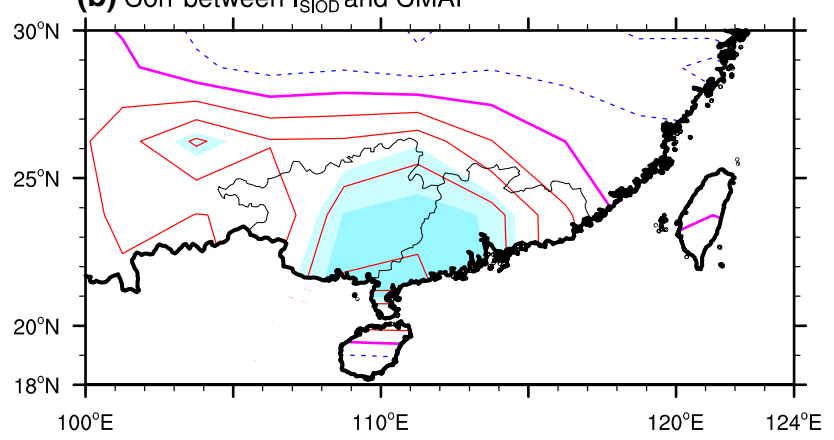

(c) Corr between $\mathrm{I}_{\mathrm{SIOD}}$ and GPCP

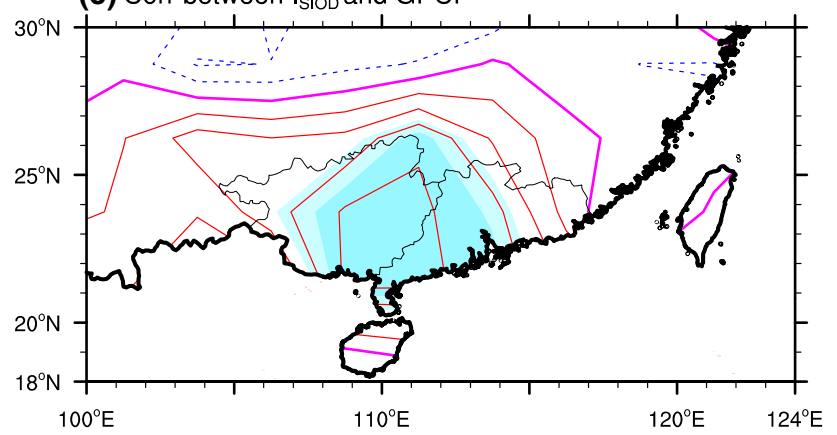

Fig. 5 Correlations of spring R-SIODP index with the southern China summer rainfall derived from (a) station-observed, (b) CMAP, and GPCP (c) data, respectively. Darker (lighter) shades indicate areas where correlation coefficients are statistically significant at/ above the 95\% (90\%) confidence level. Blue, magenta and red lines indicate negative, zero and positive contour values respectively. All contour intervals are 0.1

Table 2 Years when the absolute values of spring (MAM) R-SIODP index are not smaller than one standard deviation of the index

\begin{tabular}{ll}
\hline $\mathrm{I}_{\text {R-SIODP }}$ & Years \\
\hline$\geq 1$ & $1981,1987,1993,1994,2010,2015$ \\
$\leq-1$ & $1980,1983,1989,1990,1992$, \\
& $1996,2002,2012,2013$ \\
\hline
\end{tabular}

$0.42 \mathrm{~K}$. The years in which the R-SIODP index is greater (smaller) than $1(-1)$ times of the standard deviation were selected as the high (low) R-SIODP index years (Table 2).

\subsection{Persistence of R-SIODP from spring to summer}

To reveal the impact of R-SIODP on $\mathrm{P}_{\mathrm{GG}}$, anomalous circulations in the lower troposphere were presented in Fig. 6. The atmosphere responded to the forcing of the SSTA of R-SIODP in the South Indian Ocean. In the spring, easterly winds prevailed at $850 \mathrm{hPa}$ in the lower levels of the troposphere over the low latitudes of the southern hemisphere (Fig. 6a) whereas westerly winds prevailed in the low latitudes of the northern hemisphere. Meanwhile, GG was under the control of anomalous southwesterly winds, which are conducive to rainfall in southern China. When the easterly anomaly appeared over the equatorial Indian Ocean and the oceanic region to the northwest of Australia, it was favorable for the occurrence of the off-coastal current in the equatorial southeastern Indian Ocean and caused a cold SSTA there (Fig. 6b). This is similar to the formation mechanism of the SSTA in the equatorial southeastern Indian Ocean during positive IOD events as proposed by Saji et al. (1999). In the subtropical region of the southern hemisphere, this is also consistent with the SIOD formation mechanism of the airsea interaction, as proposed by Behera and Yamagata (2001). As shown in Fig. 6b, in the South Indian Ocean, there existed positive SSTAs in the western pole area of the R-SIODP and negative SSTAs in the eastern pole area. These SSTAs were located in the region near $30^{\circ} \mathrm{S}$ (with a northerly anomaly) and the tropical regions (with an easterly anomaly), respectively. The atmosphere responded to the SSTA anomalously. At $850 \mathrm{hPa}$, an anomalous convergence was observed over the western pole and an anomalous divergence was found over the eastern pole (Fig. 6b). An anti-cyclonic circulation anomaly was observed over the South Indian Ocean, leading to the intensification and southwestward shift of the Mascarene high (Feng et al. 2014).

The SSTA pattern occurred in the spring could still maintain in the summer. Regarding the multi-year mean climatology, the circulation pattern in boreal summer looks similar to that in boreal spring except that the cross-equatorial Somali current significantly enhances in the summer (Fig. 6c). At $850 \mathrm{hPa}$, no large changes were found in both patterns of the anomalous circulation and SSTA distributions over the southern Indian Ocean from the spring to the summer (Fig. 6b, d) except for small changes in the value and significance level. In the spring, the southerly winds weakened at the western pole of the R-SIODP, and the southeasterly trade wind strengthened at the eastern pole of the R-SIODP. The WES feedback mechanism (Xie and Philander 1994) causes weakened evaporation at the western pole (Wu and Yeh 2010) of the R-SIODP and enhanced evaporation at the eastern pole, therefore inducing a sustained positive SSTA at the western pole and a sustained negative SSTA at the eastern pole in the summer (Fig. 6d) (Behera and Yamagata 2001; Xu et al. 2013). 
(a) MAM Climatological SST and 850-hPa V

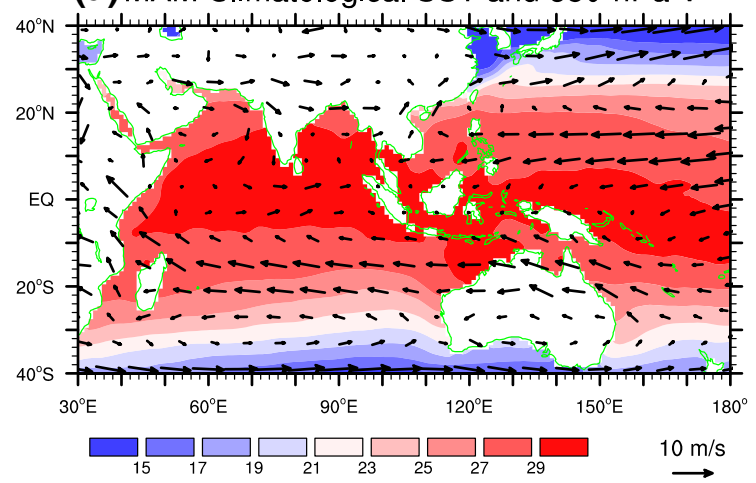

(c) JJA Climatological SST and 850-hPa V

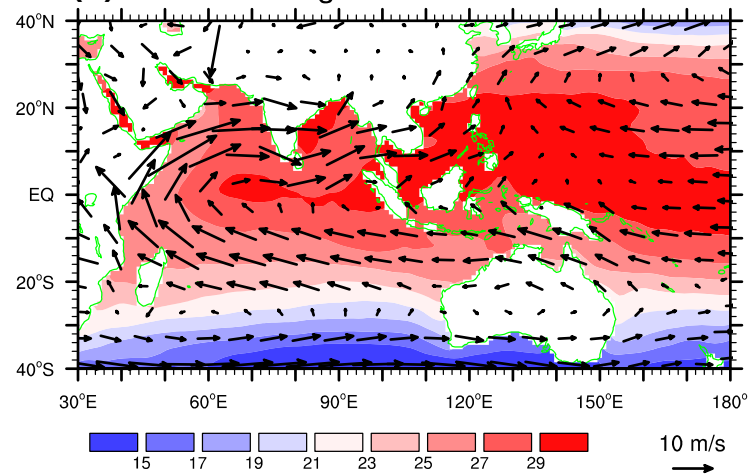

(b) MAM SST and 850-hPa V

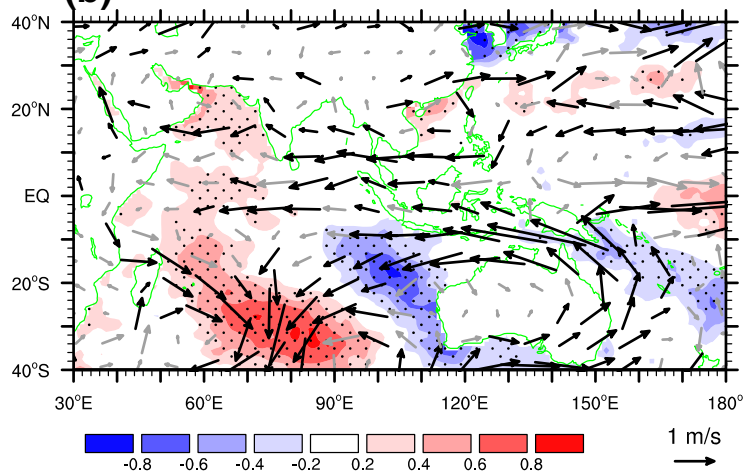

(d) JJA SST and 850-hPa V

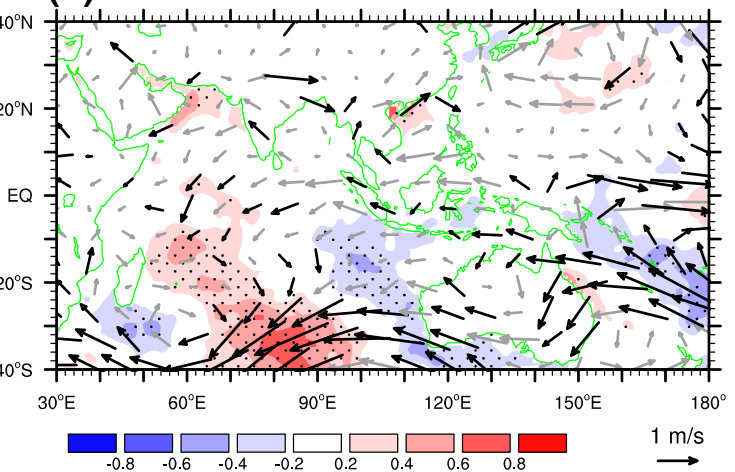

Fig. 6 Multiyear mean climatology of SST (shaded, in K) and winds (vectors) at $850 \mathrm{hPa}$ during spring (a), and composite differences between of SSTA (shaded) along with anomalous winds at $850 \mathrm{hPa}$ (vectors) in high spring R-SIODP index years from these in low index years (b). Stippled/Bold vectors are for the SSTA/winds significant at/ above $95 \%$ level of confidence using a $t$ test. $\mathbf{c}$ and $\mathbf{d}$ are same as in (a) and (b), respectively but for summer

Table 3 Composite the anomalous oceanic mixed layer heat budget and its different terms (K/month) in high spring R-SIODP index years from these in low index years averaged over the western and eastern R-SIODP poles

\begin{tabular}{llcccrr}
\hline Regions & $\frac{\partial T^{\prime}}{\partial t}$ & Latent heat & $\begin{array}{l}\text { Shortwave radia- } \\
\text { tion }\end{array}$ & Ocean advection & Ocean upwelling & Residual \\
\hline Eastern pole & -0.026 & -0.035 & -0.010 & 0.011 & 0.001 & 0.007 \\
Western pole & 0.025 & 0.041 & 0.014 & 0.019 & -0.053 \\
\hline
\end{tabular}

Shortwave radiation is the difference between downward and upward shortwave radiation

These anomalies of spring R-SIODP SST can continue to the summer, and force anomalous atmospheric circulation in response to the SSTA in the summer.

In order to further understand the role of evaporation in the persistence of R-SIODP from the spring to the summer, the anomalous mixed layer heat budget over the eastern and western poles were diagnosed (Table 3). It was found that the anomalous surface latent heat flux in eastern pole was negative and its magnitude was comparable to the anomalous tendency of the ocean mixed layer temperature (Table 3), whereas contributions from the other three terms were relative small. This indicates that the latent heat flux is a crucial factor in the decrease of the SSTA over the eastern pole of R-SIODP. For the western pole, although anomalous net surface shortwave radiation and ocean advection partly contributed to the increase in SSTA, the anomalous latent heat flux was greater than the sum of the former two terms (Table 3). This also suggests that the latent heat flux is crucial in the increase of the SSTA over the western pole of R-SIODP.

\subsection{Impacts of summer R-SIODP on circulation anomalies}

The sustained SSTA pattern existed in South Indian Ocean in JJA. The negative SSTA over the eastern pole resulted 
in a pair of anomalous anti-cyclonic circulations that were located to the south and north of the equator, respectively (Fig. 6d) (Matsuno 1966; Gill 1980). The anomalous anticyclonic circulation to the south of the equator induced an abnormal southeasterly flow on its eastern flank, enhancing the cross-equatorial flow near $105^{\circ} \mathrm{E}$ (Fig. 6c). If an index of cross-equatorial flow $\left(\mathrm{I}_{\mathrm{CEF}}\right)$ at $105^{\circ} \mathrm{E}$ was defined as the anomalous meridional winds averaged over $\left[100^{\circ} \mathrm{E}-105^{\circ} \mathrm{E}\right.$, $\left.3^{\circ} \mathrm{S}-1^{\circ} \mathrm{N}\right]$, it could be found that the correlation between $\mathrm{I}_{\mathrm{CEF}}$ and $\mathrm{I}_{\mathrm{R}-\mathrm{SIODP}}$ is significant with a value of 0.42 . This significant correlation could be explained as follows. The cooling in the eastern pole of R-SIODP forced the atmosphere to respond, yielding a higher than normal surface air pressure there. As a result, anomalous pressure gradient pointing northward was generated, which subsequently induced the ageostrophic cross-equatorial motion. On the other hand, the cooling SSTA in the eastern pole also induced descending motions along with the anomalous divergence in the lower troposphere such as at $850 \mathrm{hPa}$. The anomalous divergent flows crossed the equator and entered the northern hemisphere. The cross-equatorial flow at $105^{\circ} \mathrm{E}$ thus strengthened.

Some studies reported that the cross-equator flow near $105^{\circ} \mathrm{E}$ has an important impact on the drought and flood events in eastern part of China including GG (Shi et al. 2001; Gao and Xue 2006; Li and Li 2014). As shown in Fig. $6 \mathrm{~d}$, when the cross-equator flow near $105^{\circ} \mathrm{E}$ strengthened, the anomalous anti-cyclonic circulation over the South China Sea (SCS) intensified. This relation can be further examined by the correlation of cross-equator flow index $\mathrm{I}_{\mathrm{CEF}}$ and the vorticity over SCS at $850 \mathrm{hPa}$. The index of vorticity over SCS can be defined by the $850 \mathrm{hPa}$ vorticity averaged in $\left[100^{\circ} \mathrm{E}-120^{\circ} \mathrm{E}, 0^{\circ}-18^{\circ} \mathrm{N}\right]$. It was found that the correlation was significant with a value of -0.55 .

The intensified anomalous anti-cyclonic circulation over the SCS in the summer influences the summer rainfall in GG region. Climatologically, there exist westerly winds over the SCS at $850 \mathrm{hPa}$ in boreal summer as shown in Fig. 6c. The Rossby waves may disperse energy northward from the SCS into GG region, where an anomalous cyclonic circulation is triggered. A circulation pattern similar to this was observed in 1994 when a strong positive IOD event occurred that year as discussed in Guan and Yamagata (2003). It was found that the wave activity fluxes (Takaya and Nakamura 2001, TN fluxes) associated with quasi-stationary Rossby waves over the SCS show clearly northward propagation of waves although the fluxes were not so large. Table 4 shows these fluxes along $115.5^{\circ} \mathrm{E}$ from $10.5^{\circ} \mathrm{N}$ to $27^{\circ} \mathrm{N}$. Positive components were found at any latitudes along $115.5^{\circ} \mathrm{E}$ except at $16.5^{\circ} \mathrm{N}$, confirming the northward propagation of wave energy. Besides, the correlation of anomalous vorticity over GG region with the vortitiy anomalies over SCS (the anomalous vorticity at $850 \mathrm{hPa}$ averaged in $\left.\left[105^{\circ} \mathrm{E}-117^{\circ} \mathrm{E}, 20^{\circ} \mathrm{N}-26^{\circ} \mathrm{N}\right]\right)$ was significant with a value of -0.60 . All the above results suggest that the intensified anomalous anti-cyclonic circulation over SCS is very important for the intensification of the anomalous cyclonic circulation over GG region and can lead to higher than normal summertime rainfall there.

\subsection{Anomalous divergence in Maritime Continent as a background condition}

The anomalous divergence around the Indonesian archipelagos to the north of Australia at $850 \mathrm{hPa}$ in June-JulyAugust is also important in inducing the anomalous anticyclonic circulation over the SCS during the positive spring R-SIODP index years. It is seen from Fig. 7a that the anomalous divergent flows emanate outward from the $\mathrm{MC}$ region and its vicinity at $850 \mathrm{hPa}$. The anomalous divergent winds in the SCS lead to the generation of the anti-cyclonic circulation there as observed in Fig. 6d. At the same time, the divergent flow in the region to the northwest of Australia (Fig. 7a) facilitates the intensification of easterly flows in the tropical southeastern Indian Ocean, resulting in cooling in SST there (Fig. 6d). The cold SSTA is important for the maintenance of the R-SIODP in the South Indian Ocean.

The divergent winds from the MC region are also in favour of maintaining the Australian High over Australia. Meanwhile, there are negative SST anomalies in the SPCZ (South Pacific Convergence Zone) region, which force the atmosphere to respond to the anomalous cooling due to these negative SSTA as per Matsuno-Gill response (Matsuno 1966; Gill 1980) and subsequently intensify the Australian High in the lower troposphere.

Therefore, the anomalous divergent winds in the MC region force the atmospheric circulation to change in the SCS and generate an anomalous ant-cyclonic circulation there. The R-SIODP that persists from boreal spring to summer intensifies the cross-equatorial flow and henceforth reinforces the anomalous anticyclone in the SCS. The reinforced anticyclonic circulation in the SCS further induces the intensification of the anomalous cyclonic circulation over GG region.

Table 4 Meridional component of TN fluxes in $\mathrm{m}^{2} \mathrm{~s}^{-2}$ at $850 \mathrm{hPa}$ along $115.5^{\circ} \mathrm{E}$ from $10.5^{\circ} \mathrm{N}$ to $27^{\circ} \mathrm{N}$

\begin{tabular}{|c|c|c|c|c|c|c|c|c|c|c|c|c|}
\hline Latitudes & $10.5^{\circ} \mathrm{N}$ & $12^{\circ} \mathrm{N}$ & $13.5^{\circ} \mathrm{N}$ & $15^{\circ} \mathrm{N}$ & $16.5^{\circ} \mathrm{N}$ & $18^{\circ} \mathrm{N}$ & $19.5^{\circ} \mathrm{N}$ & $21^{\circ} \mathrm{N}$ & $22.5^{\circ} \mathrm{N}$ & $24^{\circ} \mathrm{N}$ & $25.5^{\circ} \mathrm{N}$ & $27^{\circ} \mathrm{N}$ \\
\hline TN fluxes & 0.11 & 0.52 & 0.87 & 0.13 & -0.19 & 0.14 & 0.19 & 0.30 & 0.20 & 0.00 & 0.01 & 0.01 \\
\hline
\end{tabular}




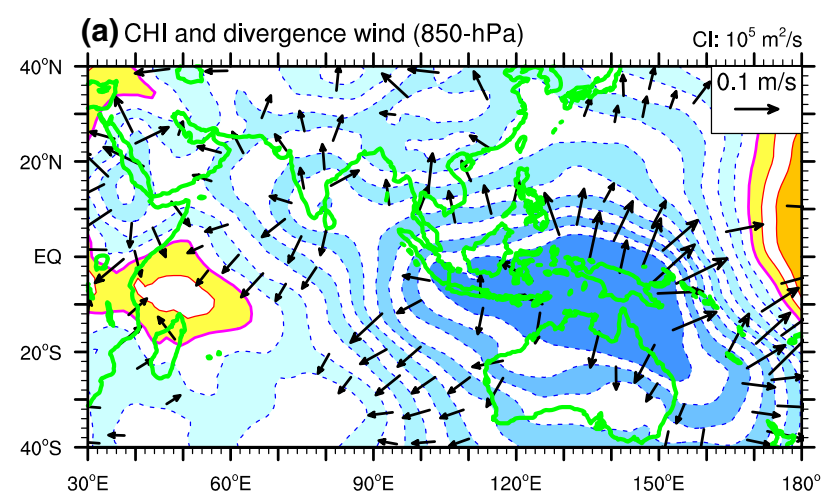

(b) $\mathrm{CHI}$ and divergence wind (150-hPa)

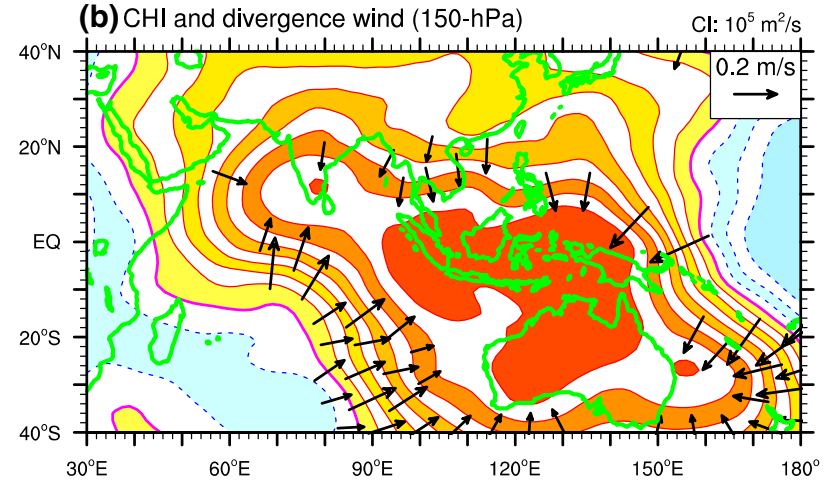

(c) $105^{\circ} \mathrm{E}-114^{\circ} \mathrm{E}$ meridional-vertical circulation

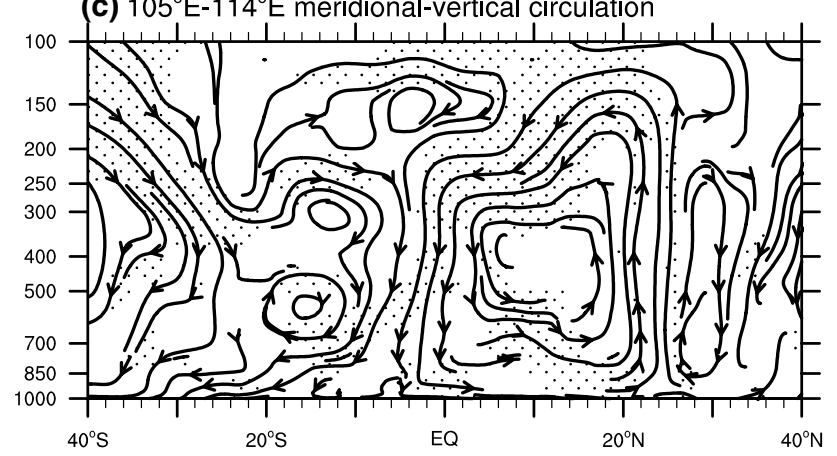

Fig. 7 The regressed summertime velocity potential (contours and shades, in $10^{5} \mathrm{~m}^{2} \mathrm{~s}^{-1}$ ) and divergent compontent of winds (vectors, in $\mathrm{ms}^{-1}$ ) at $850 \mathrm{hPa}(\mathbf{a})$ and $150 \mathrm{hPa}(\mathbf{b})$, which are obtained by regressing the corresponding variables onto the springtime index of R-SIODP. Shown in (c) is the regressed meridional vertical circulation averaged over $\left[105^{\circ} \mathrm{E}-114^{\circ} \mathrm{E}\right]$. Divergent compontent of winds above $90 \%$ condence level using an F-test in (a) and (b) are shown with bold arrows. Areas where the anomalous vertical velocity exceeds $90 \%$ confidence level in (c) are stippled

In addition, it was found that a low level anomalous convergence (Fig. 7a) and a high level anomalous divergence (Fig. 7b) occurred in GG and the western pole area of R-SIODP. The anomalous meridional-vertical circulation averaged over $105^{\circ}-114^{\circ} \mathrm{E}$ (Fig. 7c) indicated a weakened local Hadley circulation with anomalous descending motions over the equator and anomalous ascending motions in the GG area $\left(20^{\circ} \mathrm{N}-25^{\circ} \mathrm{N}\right)$, which was conducive to the positive summer rainfall anomaly in GG.

\subsection{Anomalies of water vapor transport}

The R-SIODP has impacts on water vapour transport that facilitates the anomalous rainfall in GG region. Figure 8 exhibits the multi-year mean summer climatology of vertically integrated water vapor flux and flux anomalies. The climatological average of water vapor flux integrated over the entire column (Fig. 8a) shown in Fig. 8 indicates that the water vapor is mainly transported from the southern hemisphere to the northern hemisphere near $105^{\circ} \mathrm{E}$ besides the transport by the cross-equator Somali current. The difference in the summer water vapour flux transport between high and low spring R-SIODP index years (Fig. 8b) shows large anomalous water vapor transport from northwestern Australia to the South China Sea via Sumatra Island, which is consistent with the enhanced cross-equatorial flow near $105^{\circ} \mathrm{E}$ (Fig. $6 \mathrm{~d}$ ). In addition, it was found that northwestern Australia and the MC region are regions of water vapor flux divergence anomaly and that GG is a region of water vapor flux convergence anomaly (Fig. 8b). This distribution is conducive to the positive summer rainfall anomaly in the GG area.

In summary, because the positive spring R-SIODP anomaly can persist into summer, the anomalous anticyclonic circulation above the South China Sea is reinforced through the Matsuno-Gill response, and the cross-equator flow near $105^{\circ} \mathrm{E}$ is also enhanced. As a result, the water vapor flux convergence from the southern hemisphere to the GG area also abnormally intensifies. This phenomenon enhances the anomalous ascending motion in GG, which is conducive to the positive rainfall anomaly in the GG area.

\section{Seasonal prediction model for GG summer rainfall}

The spring R-SIODP index can be used for the seasonal prediction of the GG summer rainfall anomaly. Here, we use $\sigma_{\mathrm{PGG}}$ and $\sigma_{\mathrm{R} \text {-SIODP }}$ to represent the root mean squares (RMS) of $\mathrm{P}_{\mathrm{GG}}$ and the spring R-SIODP index, respectively. Let Prr represent the remainder of $\mathrm{P}_{\mathrm{GG}}$. Then $\mathrm{P}_{\mathrm{GG}}$ consists of the part predicted by the spring R-SIODP index and Prr, written as follows:

$P_{G G}=r \cdot \sigma_{P_{G G}} \cdot \frac{I_{R-S I O D P}}{\sigma_{R-S I O D P}}+P_{r r}$

Because the correlation coefficient between the spring $\mathrm{I}_{\mathrm{R} \text {-SIODP }}$ and $\mathrm{P}_{\mathrm{GG}}$ is 0.52 , according to Eq. (4), the rainfall variability predicted by $\mathrm{I}_{\mathrm{R} \text {-SIODP }}$ can explain $27.04 \%$ of the $\mathrm{P}_{\mathrm{GG}}$ variance. 
(a) JJA Climatological water vapor and divergence

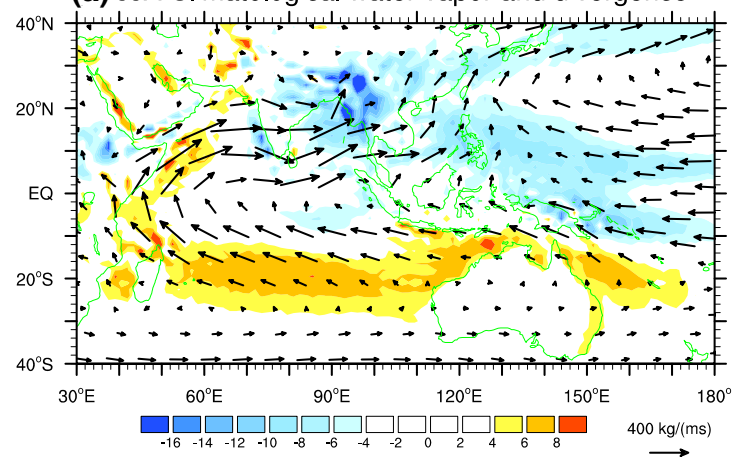

Fig. 8 Multiyear mean climatology of water vapor fluxes integrated from the earth surface up to $300 \mathrm{hPa}$ (in $\mathrm{kg} / \mathrm{ms}$; vectors) and their divergence (in $10-5 \mathrm{~kg} / \mathrm{ms}^{2}$, shaded, shades) (a), and the vertically (b) JJA water vapor and divergence

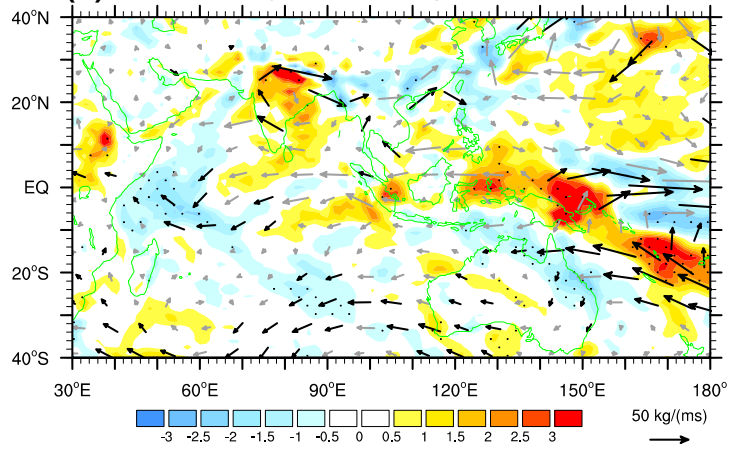

integrated anomalous vapor fluxes and their divergence (b). The fluxes with values significant above $90 \%$ level of confidence in (b) are bolded

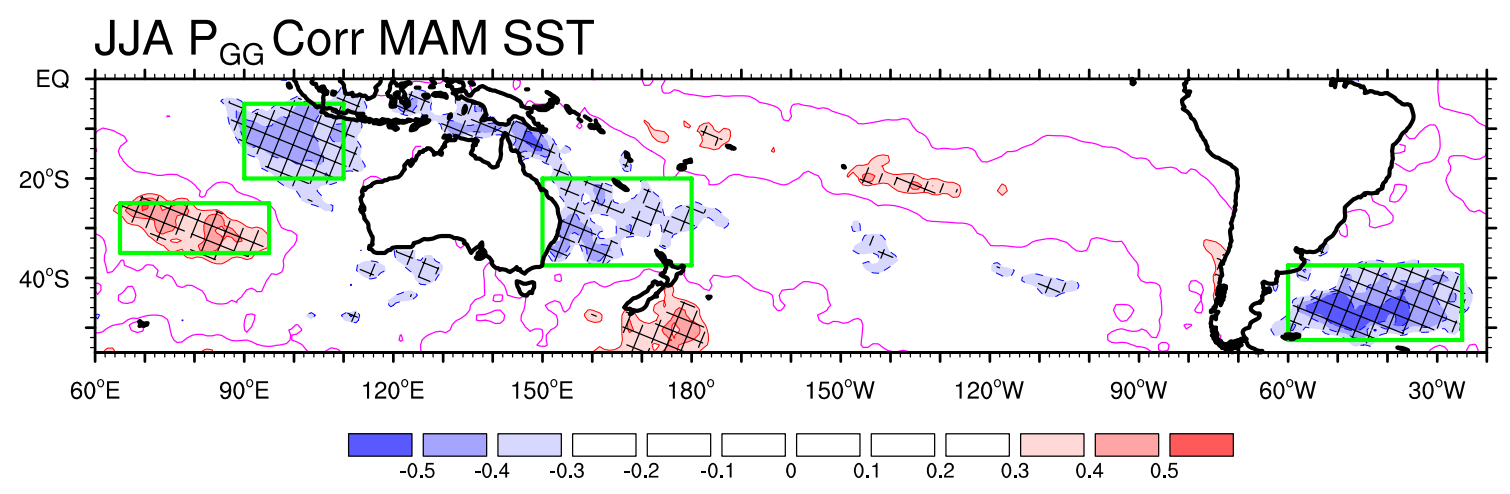

Fig. 9 Correlations of summer rainfall over GG region with the spring SSTA in the southern hemisphere. Hatched shades are for values exceeding $95 \%$ confidence level using a $t$ test

To improve the historical fitting probability of the predicted rainfall variability, we selected more predictors besides $\mathrm{I}_{\text {R-SIODP. }}$ Firstly, it has been found that the spring NAO can have impacts on the summer rainfall anomaly in eastern China by modulating the East Asian summer monsoon activity (Wu et al. 2009). The springtime NAO index was thus selected as one of the predictors. Secondly, it is necessary to further examine the relations of PGG and springtime SSTA in other regions. Figure 9 presents the correlation of $\mathrm{P}_{\mathrm{GG}}$ with spring SSTA in the southern hemisphere. It can be seen from Fig. 9 that, besides the R-SIODP, there are two other regions with high correlation coefficient, indicating that $\mathrm{P}_{\mathrm{GG}}$ is possibly affected by the springtime SSTA in these regions. These two regions are located to the east of Australia (EAus) and to the east of southern Africa (EAfr), respectively. Some researchers (Zhou 2011; Wu et al. 2015) reported that SSTAs in earlier season in both EAus and EAfr could affect the summer rainfall anomaly in eastern China. Thus, the SSTA averaged over EAus and EAfr were selected as the other two predictors besides the R-SIODP index. Finally, the spring
Table 5 Correlation coefficients of springtime predictors with summer rainfall averaged over GG region

\begin{tabular}{llllll}
\hline Time-series & $\mathrm{P}_{\mathrm{GG}}$ & $\mathrm{I}_{\mathrm{R}-\text { SIODP }}$ & $\mathrm{I}_{\text {EAus }}$ & $\mathrm{I}_{\text {EAfr }}$ & $\mathrm{I}_{\mathrm{NAO}}$ \\
\hline $\mathrm{P}_{\mathrm{GG}}$ & 1 & 0.52 & -0.40 & -0.59 & -0.35 \\
$\mathrm{I}_{\mathrm{R}-\mathrm{SIODP}}$ & & 1 & -0.24 & -0.13 & -0.14 \\
$\mathrm{I}_{\text {EAus }}$ & & & 1 & 0.04 & -0.30 \\
$\mathrm{I}_{\text {EAfr }}$ & & & & 1 & 0.37 \\
$\mathrm{I}_{\mathrm{NAO}}$ & & & & & 1 \\
\hline
\end{tabular}

The critical values at $99 \%$ (95\%) levels of confidence are found to be $0.42(0.33)$

R-SIODP index, the regional averages of SSTA over EAus and EAfr, and the NAO index are used as the predictors in the statistical model. The correlation coefficients between the different indices and GG summer rainfall were shown in Table 5.

Because the predictors are not independent of each other (Table 5), the step-wise regression method is applied to 
establish the regression equation. The regression model that uses the above four predictors is written as:

$P_{G G}=0.34 \cdot X_{1}-0.38 \cdot X_{2}-0.43 \cdot X_{3}-0.43 \cdot X_{4}$

where $\mathrm{X}_{1}$ is the spring R-SIODP index, $\mathrm{X}_{2}$ is the spring EAus index, $\mathrm{X}_{3}$ is the spring EAfr index, and $\mathrm{X}_{4}$ is the spring NAO index. The hindcasted $\mathrm{P}_{\mathrm{GG}}$ was displayed in Fig. 10.

The hindcasted $\mathrm{P}_{\mathrm{GG}}$ using model Eq. (5) varies very similar to the interannual variation of the observed precipitation in GG region. (Fig. 10); the correlation between the hindcasted time series of $\mathrm{P}_{\mathrm{GG}}$ and the observed time series was found to be 0.82 (above the 99\% confidence level). This high correlation means that about $67.24 \%$ of the total variance of the observed $\mathrm{P}_{\mathrm{GG}}$ can be explained by the hindcasted results. This suggests that the multiple linear regression model (hereafter, prediction model) can well reproduce the observed interannual variation in $\mathrm{P}_{\mathrm{GG}}$.

To examine whether the regression coefficients would change greatly or not for different periods of time, the statistical cross validation (CV) tests (Wilks 1995) for the prediction model were performed over 5 periods of time. For example, the summertime $\mathrm{P}_{\mathrm{GG}}$ was hindcasted for a period of 7 years from 1979 to 1985 using the CV model (a). We built the CV model (a) with 4 predictors by performing the step-wise regressions based on observed data over the period of $1986-2015$, i.e. the last 30 years of 37 years from 1979 to 2015 . The equation of CV model (a) was listed in Table 6. Other four CV models from (b) to (e) (Table 6) were similarly constructed for the hindcasted $\mathrm{P}_{\mathrm{GG}}$ for 1986-1992, 1993-1999, 2000-2006, and 2007-2015, respectively. From Table 6, it was found that the hindcasted $\mathrm{P}_{\mathrm{GG}}$ can explain more than $50 \%$ of the total variance of the observed $\mathrm{P}_{\mathrm{GG}}$ in most periods. Using these $5 \mathrm{CV}$ models, the time series of $\mathrm{P}_{\mathrm{GG}}$ were hindcasted and presented in Fig. 11a-e, respectively.

The hindcasted time-series of $\mathrm{P}_{\mathrm{GG}}$ are in accordance with the observed $\mathrm{P}_{\mathrm{GG}}$. As seen in Fig. 11a-e, for each period of 7 or 9 years, the hindcasted variation of $\mathrm{P}_{\mathrm{GG}}$ was consistent with the variation of observed GG rainfall. For the 37 years from 1979 to 2016, the connected time-series of $\mathrm{P}_{\mathrm{GG}}$ hindcasted by these $5 \mathrm{CV}$ models (short-dashed curves in Fig. 10) is highly correlated with the observed time-series of $\mathrm{P}_{\mathrm{GG}}$ with a correlation coefficient of 0.76 , demonstrating a successful prediction of GG rainfall though the correlation is a little smaller than 0.82 , which is related to prediction model Eq. (5) as mentioned above.

The above results demonstrate that the prediction model established using the spring R-SIODP index, the EAus SSTA, the EAfr SSTA, and the NAO index is successful. Therefore, this model can be used for practical predict of the future interannual variability of $\mathrm{P}_{\mathrm{GG}}$.

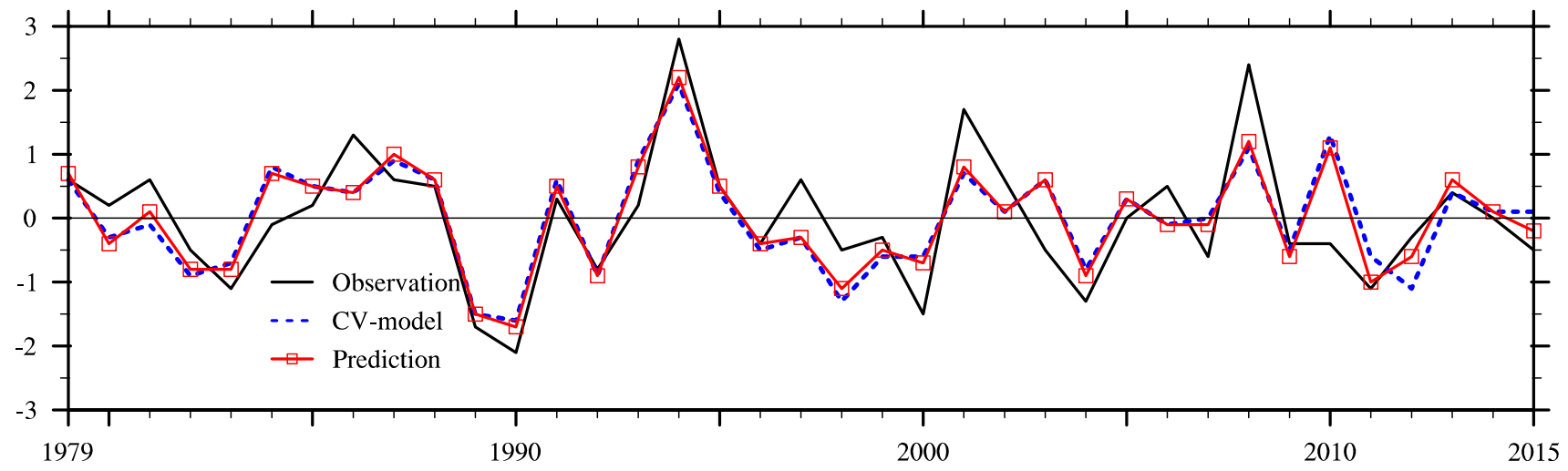

Fig. 10 Time series of observed (thick solid) summer rainfall over GG region and hindcasted $\mathrm{P}_{\mathrm{GG}}$ (solid with open squares) using regression model Eq. (3) for 37 years from 1979 through to 2015

Table 6 The CV models and the variances explained by hindcasted results

\begin{tabular}{llll}
\hline CV models & Model equations & Hindcast for periods & $\begin{array}{l}\text { Variance } \\
\text { explained } \\
(\%)\end{array}$ \\
\hline (a) & $\mathrm{P}_{\mathrm{GG}}=0.28 * \mathrm{X}_{1}-0.42 * \mathrm{X}_{2}-0.50 * \mathrm{X}_{3}-0.44 * \mathrm{X}_{4}$ & $1979-1985$ & 36.39 \\
(b) & $\mathrm{P}_{\mathrm{GG}}=0.34 * \mathrm{X}_{1}-0.38 * \mathrm{X}_{2}-0.38 * \mathrm{X}_{3}-0.48 * \mathrm{X}_{4}$ & $1986-1992$ & 87.86 \\
(c) & $\mathrm{P}_{\mathrm{GG}}=0.33 * \mathrm{X}_{1}-0.43 * \mathrm{X}_{2}-0.41 * \mathrm{X}_{3}-0.47 * \mathrm{X}_{4}$ & $1993-1999$ & 77.56 \\
(d) & $\mathrm{P}_{\mathrm{GG}}=0.32 * \mathrm{X}_{1}-0.42 * \mathrm{X}_{2}-0.37 * \mathrm{X}_{3}-0.43 * \mathrm{X}_{4}$ & $2000-2006$ & 54.46 \\
(e) & $\mathrm{P}_{\mathrm{GG}}=0.50 * \mathrm{X}_{1}-0.20 * \mathrm{X}_{2}-0.48 * \mathrm{X}_{3}-0.26 * \mathrm{X}_{4}$ & $2007-2015$ & 30.60 \\
\hline
\end{tabular}


(a)

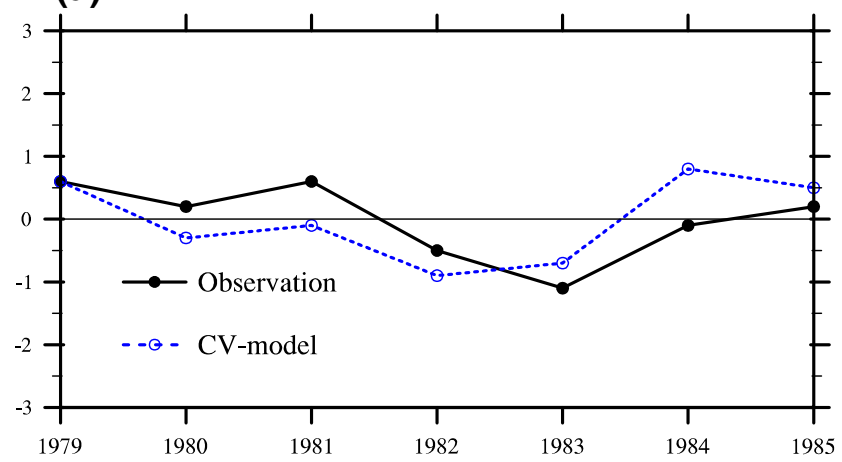

(c)

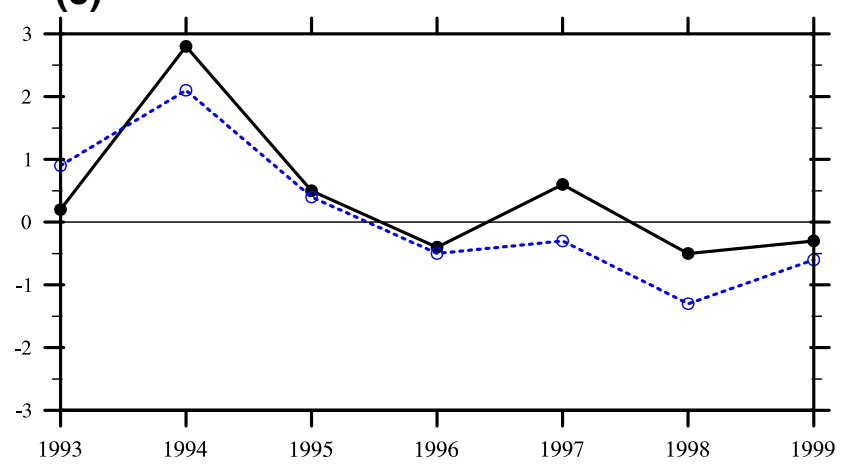

(b)

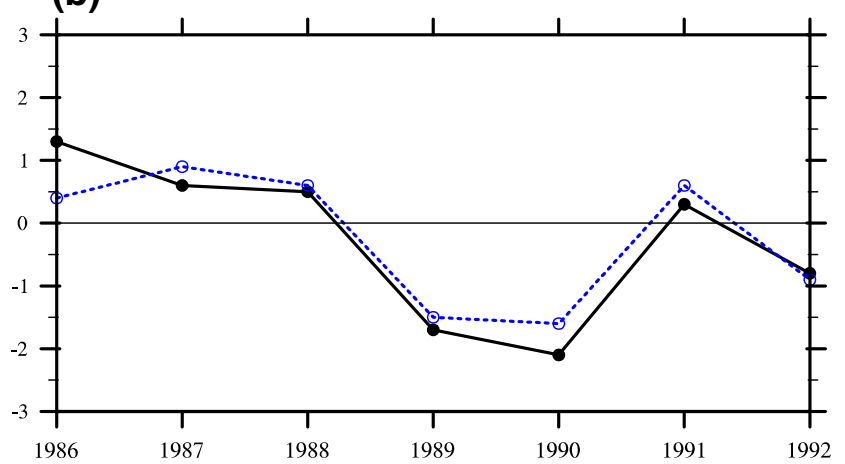

(d)

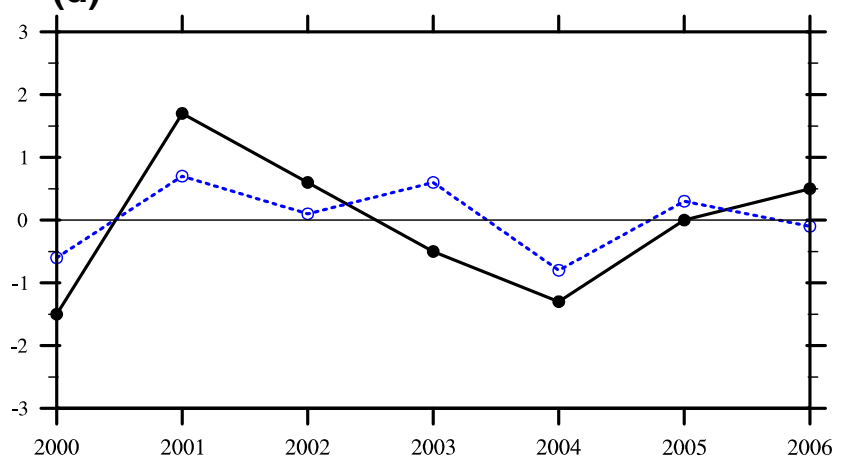

(e)

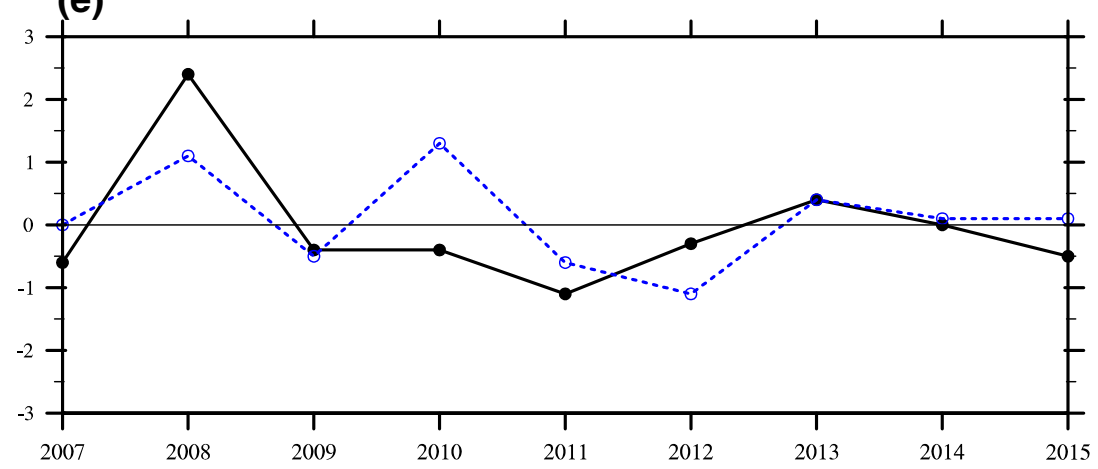

Fig. 11 Time series of predicted (short dashed) and observed (thick solid) summer rainfall over GG region by using five Cross validation models ( $\mathrm{CV}$ model) developed for the prediction of $\mathrm{P}_{\mathrm{GG}}$ in peri-

ods 1979-1985 (a), 1986-1992 (b), 1993-1999 (c), 2000-2006 (d), 2007-2015 (e), respectively. The time-series of hindcasted $\mathrm{P}_{\mathrm{GG}}$ in (a)-(e) are connected and presented in Fig. 10 (short-dashed)

\section{Conclusions and discussion}

Based on the aforementioned analyses, we presented the following conclusions.

There exists a SIOD-like SSTA pattern in South Indian Ocean in boreal spring, which may affect the variation of summertime rainfall in GG region. This pattern is referred to as R-SIODP. An index to describe R-SIODP is defined as the difference between the regional mean SSTA averaged over area $\left[65^{\circ} \mathrm{E}-95^{\circ} \mathrm{E}, 35^{\circ} \mathrm{S}-25^{\circ} \mathrm{S}\right]$ and that over $\left[90^{\circ} \mathrm{E}-110^{\circ} \mathrm{E}, 20^{\circ} \mathrm{S}-5^{\circ} \mathrm{S}\right]$ after the ENSO signal in the preceding winter is removed. It is found that the anomalous summertime GG rainfall is significantly and positively correlated with R-SIODP index during both boreal spring and summer. When R-SIODP index is in its positive (negative) years, the summer rainfall is abnormally sufficient (deficient) in GG.

The spring R-SIODP anomaly persists into summer though the WES feedback mechanism. During positive R-SIODP index years, this persistent SSTA pattern leads to the anomalously intensified divergent winds in the eastern pole of the R-SIODP in the lower troposphere. The 
intensified divergent flow is in favor of the enhancement of cross-equator flow near $105^{\circ} \mathrm{E}$, and hence facilitates the anomalous anti-cyclonic circulation to reinforce over the $\mathrm{SCS}$ at $850 \mathrm{hPa}$. Higher than normal water vapor is transported from the eastern pole of the R-SIODP into the SCS and GG region via the enhanced cross-equator flow near $105^{\circ} \mathrm{E}$. The anomalous anticyclonic circulation over the SCS disperses wave energy northward, inducing the anomalous cyclonic circulation over GG region, where higher than normal rainfall is subsequently induced.

A statistical prediction model is constructed using the spring R-SIODP index, the EAus index, the EAfr index, and the NAO index. This model can well reproduce the interannual variation of the observed rainfall in GG with a historical fitting probability of $67 \%$. Thereby this regression model can be put into practical use.

In this paper, only the impact of the spring R-SIODP on the interannual variability of the GG summer rainfall anomaly is analyzed. The mechanisms behind the time evolution of R-SIODP or the SIOD-like pattern from boreal fall/winter to the subsequent summer have not been clarified yet. Furthermore, there are also significant decadal changes in GG summer rainfall. Whether the R-SIODP would affect the decadal variation of GG summer rainfall and the related physical mechanisms have not been fully studied. It should be noted that R-SIODP and SIOD differ in the geographic locations of the western and eastern poles and the temporal variations. The correlation coefficient between the SIOD index and $\mathrm{I}_{\mathrm{R} \text {-SIODP }}$ is 0.43 in the spring, whereas it is only 0.17 in the summer. The physical connection between the spring SIOD index and $\mathrm{I}_{\mathrm{R} \text {-SIODP }}$ has not been understood. All these issues mentioned above deserve further studies.

Note that the variation of summer rainfall in GG is also linked to IOD (Guan and Yamagata 2003) and ENSO (Wu et al. 2012, 2014; Wang and Gu 2016). In this study, the R-SIODP has been demonstrated to be closely related to anomalous summer rainfall in GG after the preceding winter ENSO signal has been removed out. Considering the three quantities including the $\mathrm{P}_{\mathrm{GG}}$, index of R-SIODP, and IOD index, it is found that partial correlation between $\mathrm{P}_{\mathrm{GG}}$ and the index of R-SIODP is $0.44(0.42)$ for boreal spring (summer), whereas the partial correlation between $\mathrm{P}_{\mathrm{GG}}$ and IOD index is only $-0.07(-0.04)$. This indicates that R-SIODP is more important than IOD in modulating the rainfall anomaly in GG region. From the perspective of dynamics, there still exist some issues that are not clear and need further in-depth investigations.

Furthermore, in this work, we have discussed how the precursory SSTA over the eastern pole of the R-SIODP influences the subsequent summer rainfall anomalies in the Guangdong-Guangxi region. Theoretically, either of the two poles may induce the similar teleconnection. However, compared to the eastern pole that is located in the region where the mean climatological easterly at $850 \mathrm{hPa}$ prevails, the western pole is located in a region where the mean climatological anticyclone at $850 \mathrm{hPa}$ occupies above the south Indian Ocean and is a little far from the equator. This suggests that the influences of the eastern pole and western pole regions on the northern hemisphere climate are possibly different. To further clarify these different influences, numerical simulations need to be carried out to examine teleconnections triggered by the western pole and role of this western pole in maintaining the negative SSTA in the eastern pole.

Acknowledgements This work was jointly supported by Natural Science Foundation of China (41330425), the China Meteorological Administration Special Public Welfare Research Fund Province (GYHY201406024), Natural Science Foundation of Jiangsu Province of China (BK20160956), Specialized Research Fund for the Doctoral Program of Higher Education (Grant No. 21033228110001), Project Funded by the Priority Academic Program Development of Jiangsu Higher Education Institutions (PAPD), and the Startup Foundation for Introducing Talent of NUIST (Grant No. 2014r006, 2015r035). The authors thank $\mathrm{PhD}$ candidate Mingcheng Chen (NUIST, China) for helpful discussion about the oceanic mixed layer heat budget analysis.

Open Access This article is distributed under the terms of the Creative Commons Attribution 4.0 International License (http:// creativecommons.org/licenses/by/4.0/), which permits unrestricted use, distribution, and reproduction in any medium, provided you give appropriate credit to the original author(s) and the source, provide a link to the Creative Commons license, and indicate if changes were made.

\section{References}

Adler RF, Huffman GJ, Chang A et al (2003) The version-2 global precipitation climatology project (GPCP) monthly precipitation analysis (1979-present). J hydrometeorol 4(6):1147-1167

Behera S, Yamagata T (2001) Subtropical SST dipole events in the southern Indian Ocean. Geophys Res Lett 28:327-330

Cao J, Yao P, Wang L et al (2014) Summer rainfall variability in lowlatitude highlands of China and subtropical Indian Ocean dipole. J Climate 27(2):880-892

Chan JCL, Zhou W (2005) PDO, ENSO and the early summer monsoon rainfall over South China. Geophys Res Lett 32:L08810. doi:10.1029/2004GRL022015

Chen JP, Wen ZP, Wu R, Chen Z, Zhao P (2014a) Interdecadal changes in the relationship between Southern China winterspring precipitation and ENSO. Clim Dyn 43:1327-1338

Chen Z, Wen ZP, Wu R, Zhao P, Cao J (2014b) Influence of two types of El Niños on the East Asian climate during boreal summer: a numerical study. Clim Dyn 43:469-481

Chen M, Li T, Shen X, Wu B (2016) Relative roles of dynamic and thermodynamic processes in causing evolution asymmetry between El Niño and La Niña. J Climate 29:2201-2220

Dee DP et al. (2011) The ERA-Interim reanalysis: Configuration and performance of the data assimilation systems. Quart J Roy Meteor Soc 137(656):553-597

Duan W, Song L, Li Y et al (2013) Modulation of PDO on the predictability of the interannual variability of early summer rainfall over south China. J Geophy Res Atmos 118(23):13,008-13,021 
Feng J, Hu D, Yu L (2014) How does the Indian Ocean subtropical dipole trigger the tropical Indian Ocean dipole via the Mascarene high? Acta Oceanol Sin 33:64-76

Gao H, Xue F (2006) Seasonal variation of the cross-equatorial flows and their influences on the onset of South China Sea summer monsoon. Clim Environ Res 11(1):57-68 (in Chinese)

Gill AE (1980) Some simple solutions for the heat induced tropical circulation. Q J R Meterol Soc 106(449):447-462

Gong D, Wang S (1999) Definition of antarctic oscillation index. Geophys Res Lett 26(4):459-462

Guan Z, Jin D (2013) Extreme events in seasonal mean winter rainfall over East China during the past three decades. Atmos Oceanic Sci Lett 6:240-247

Guan Z, Yamagata T (2003) The unusual summer of 1994 in East Asia: IOD teleconnections. Geophys Res Lett 30:1544-1547. doi:10.1029/2002GL016831

Guan Z, Han J, Li M (2011) Circulation patterns of regional mean daily precipitation extremes over the middle and lower reaches of the Yangtze River during the boreal summer. Clim Res 50:171-185

$\mathrm{He} \mathrm{Z}, \mathrm{Wu} \mathrm{R}$ (2014) Indo-Pacific remote forcing in summer rainfall variability over the South China Sea. Clim Dyn 42:2323-2337

Hsu H, Lin S (2007) Asymmetry of the Tripole rainfall pattern during the East Asian summer. J Climate 20(17):4443-4458

Huo L, Jin D (2016) The interannual relationship between anomalous precipitation over southern China and the south eastern tropical Indian Ocean sea surface temperature anomalies during boreal summer. Atmos Sci Lett 17:610-615.

Hurrell JW (1995) Decadal trends in the North Atlantic oscillation: regional temperatures and precipitation. Science 269(5224):676-679

Ishii M, Shouji A, Sugimoto S, Matsumoto T (2005) Objective analyses of sea-surface temperature and marine meteorological variables for the 20th century using ICOADS and the Kobe collection. Int J Climatol 25(7):865-879

Jin D, Guan Z, Tang W (2013) The extreme drought event during winter-spring of 2011 in East China: combined influences of teleconnection in mid-high latitudes and thermal forcing in Maritime Continent region. J Climate 26:8210-8222

Jin D, Guan Z, Cai J et al (2015) Interannual variations of regional summer precipitation in Mainland China and their possible relationships with different teleconnections in the past five decades. J Meteor Soc Jpn 93(2):267-285

Kalnay E, Kanamitsu M, Kistler R, Collins W, Deaven D, Gandin L, Iridell M, Saha S, White G, Woolen J, Zhu Y, Chelliah M, Ebisuzaki W, Higgins W, Janowiak J, Mo KC, Ropolewski C, Wang J, Leetmaa A, Reynolds R, Jenne R, Joseph D (1996) The NCEP/NCAR 40-year reanalysis project. Bull Am Meteorol Soc $77: 437-471$

Li C, Li S (2014) Interannual Seesaw between the Somali and the Australian Cross-equatorial flows and its connection to the East Asian Summer monsoon. J Climate 27:3966-3981

Mantua NJ, Hare SR, Zhang Y et al (1997) A pacific interdecadal climate oscillation with impacts on salmon production. Bull Am Meteorol Soc 78(6):1069-1079

Matsuno T (1966) Quasi-geostrophic motions in the equatorial area. J Meteorol Soc Jpn 44(1):25-43

Nan S, Li J (2003) The relationship between summer precipitation in the Yangtze River valley and the previous Southern Hemisphere annular mode. Geophys Res Lett 30(24):2266. doi:10.1029/200 3GL018381

Rayner NA et al (2003) Global analyses of sea surface temperature, sea ice, and night marine air temperature since the late nineteenth century. J Geophys Res 108(D14):4407
Reynolds RW, Rayner NA, Smith TM et al (2002) An improved in situ and satellite SST analysis for climate. J Climate 15(13):1609-1625

Saha S et al (2006) The NCEP climate forecast system. J Clim 19:3483-3517

Saji H, Goswami BN, Vinayachandran PN, Yamagata T (1999) A dipole mode in the tropical Indian Ocean. Nature 401:360-363

Shi N, Shi D, Yan M (2001) The effects of cross-equatorial current on south China Sea monsoon onset and drought/flood in East China. J Trop Meteorol 17(4):405-414 (Chinese)

Smith TM, Reynolds RW, Peterson TC, Lawrimore J (2008) Improvements to NOAA's historical merged LandOcean surface temperature analysis (1880-2006). J Clim 21(10):2283-2296

Takaya K, Nakamura H (2001) A formulation of a phaseindependent wave-activity flux for stationary and migratory quasigeostrophic eddies on a zonally varying basic flow. J Atmos Sci 58:608-627

Wang L, Gu W (2016) The Eastern China flood of June 2015 and its causes. Sci Bull 61:178-184

Wang L, Guo S, Jing G (2016) The timing of South-Asian high establishment and its relation to tropical Asian summer monsoon and precipitation over east-central China in summer. J Trop Meteorol 22(2):136-144

Wang L, Dai A, Guo S, Ge J (2017) Establishment of the South Asian high over the Indochina Peninsula during late spring to summer. Adv Atmos Sci doi:10.1007/s00376-016-6061-7(in press)

Wilks DS (1995) Statistical methods in the atmospheric sciences: an introduction. Academic Press, USA, pp 467

Wu R, Yeh S-W (2010) A further study of the tropical Indian Ocean asymmetric mode in boreal spring. J Geophys Res 115:D08101

Wu R, Kirtman B, Pegion K (2006) Local air-sea relationship in observations and model simulations. J Clim 19:4914-4932

Wu Z, Wang B, Li J, Jin F (2009) An empirical seasonal prediction model of the east Asian summer monsoon using ENSO and NAO. J Geophys Res 114:D18120

Wu R, Wen Z, Yang S et al (2010) An interdecadal change in southern China summer rainfall around 1992/93. J Clim 23(9):2389-2403

Wu R, Yang S, Wen Z et al (2012) Interdecadal change in the relationship of southern China summer rainfall with tropical IndoPacific SST. Theor Appl Climatol 108(1-2):119-133

Wu R, Huang G, Du Z, Hu K (2014) Cross-season relation of the South China sea precipitation variability between winter and summer. Clim Dyn 43:193-207

Wu Z, Dou J, Lin H (2015) Potential influence of the November-December southern hemisphere annular mode on the East Asian winter precipitation: a new mechanism. Clim Dyn 44(5-6):1215-1226

Xie P, Arkin AP (1997) Global precipitation: a 17-year monthly analysis based on gauge observations, satellite estimates, and numerical model outputs. Bull Amer Meteor Soc 78(11):2539-2558

Xie S, Philander SGH (1994) A coupled ocean-atmosphere model of relevance to the ITCZ in the eastern Pacific. Tellus A 46(4):340-350

Xie S, Hu K, Hafner J et al (2009) Indian Ocean capacitor effect on Indo-western Pacific climate during the summer following El Niño. J Clim 22(3):730-747

Xu H, Zhang L, Du Y (2013) Research progress of southern Indian Ocean dipole and its influence. J Trop Oceanogr 32(1):1-7 (Chinese)

Yang M, Ding Y (2007) A study of the impact of South Indian Ocean dipole on the summer rainfall in china. Chin J Atmos Sci 31(4):685-694 (Chinese)

Zhai J, Su BD, Krysanova V et al (2010) Spatial variation and trends in PDSI and SPI indices and their relation to streamflow in 10 large regions of China. J Clim 23(3):649-663 
Zheng F, Li J (2012) Impact of preceding boreal winter southern hemisphere annular mode on spring precipitation over south China and related mechanism (in Chinese). Chin J Geophy 55(11):3542-3557

Zhou B (2011) Linkage between winter sea surface temperature east of Australia and summer precipitation in the Yangtze river valley and a possible physical mechanism. Chin Sci Bull 56(16):1301-1307

Zou X, Zhai P, Zhang Q (2005) Variations in droughts over China: 1951-2003. Geophys Res Lett 32:L04707. doi:10.1029/200 4GL021853 